\title{
Assessment of Coral Reef Life-Form Classification Scheme using Multiresolution Images on Parang Island, Indonesia
}

\author{
Wahyu Lazuardi ${ }^{1}$, Pramaditya Wicaksono ${ }^{2, *}$ \\ ${ }^{1}$ Geospatial Information Agency, Bogor, 16911, Indonesia \\ ${ }^{2}$ Department of Geographic Information Science, Faculty of Geography, Universitas Gadjah Mada, \\ Yogyakarta, 55281, Indonesia
}

\begin{abstract}
Spatial information on the varying composition of coral reefs is beneficial for the management and preservation of natural resources in coastal areas. Its availability is inseparable from environmental management goals; however, it can also be used as a means of supporting tourism activities and predicting the emergence of certain living species. A satellite image is one of the effective and efficient data sources that provide spatial information on coral reef variations. This study aimed to evaluate the classification scheme of coral reef life-form using images with different spatial resolutions on Parang Island, Karimunjawa Islands, Central Java. These images were from PlanetScope (3m), PlanetScope resampling $(6 \mathrm{~m})$, and Sentinel-2A MSI $(10 \mathrm{~m})$, whose spatial resolutions functioned as the base for building the $3 \mathrm{~m}, 6 \mathrm{~m}$, and $10 \mathrm{~m}$ classification schemes producing 12,11 , and 9 classes, respectively. As for the classification method, it integrated both object-based and pixel-based approaches. The results showed that the highest overall accuracy (60\%) was obtained using Sentinel-2A MSI image $(10 \mathrm{~m})$, followed by PlanetScope $(3 \mathrm{~m})$ with $48 \%$ accuracy, and PlanetScope resampling $(6 \mathrm{~m})$ with $40 \%$ accuracy. This finding indicates that multiresolution images can be used to produce complex coral reef life-form maps with different levels of information details.
\end{abstract}

Keywords: Coral reef; Life-form; Planetscope; Spatial resolution; Classification scheme

\section{Introduction}

Coral reefs are one of the natural resources in coastal areas that play fundamental ecological roles for the life of marine flora and fauna (Larkum et al., 2006). If managed, preserved, and utilized optimally, coral reefs can provide many benefits for coastal communities. Their exceptional socio-economic and cultural values and interests spread beyond their function as fish habitat, including abundant sources of seafood, coastal protection, and marine tourism (Giyanto et al., 2017). Therefore, effective and efficient

*Corresponding author.

Email address : prama.wicaksono@ugm.ac.id (Pramaditya Wicaksono) 
management and monitoring of coral reefs are paramount to improve the sustainability and usefulness of these shallow-water ecosystems, especially when under a significant amount of environmental stress. In this situation, spatial information on the characteristics of benthic compositions and coral substrates becomes necessary (Hoegh-Guldberg et al., 2007). When available, this information is not only beneficial for detecting and monitoring the impact of environmental management and changes in the living patterns of marine biota due to altered environmental conditions, but it can also be used as support facilities in tourism (Dudgeon et al., 2010).

Most importantly, spatial information on coral reef life-forms is acquired for its close relationship with coastal environment dynamics, especially with several coastal environment aspects. Complex geomorphological characteristics and diverse life-form compositions can be used in biodiversity assessment. Certain life-forms are also known to affect the growth and development of organisms, particularly the abundance of fish (Madduppa et al., 2019), and some are highly sensitive to the coastal environment dynamics. Therefore, their spatial information can be the basis for monitoring, explaining the potential of and threats to coastal resources, and ultimately creating opportunities to build and grow the blue economy (Voyer et al., 2018).

Large-scale mapping and monitoring are a stepin coral reefs management and conservation (Green et al., 2000). To meet these requirements means, among others, to utilize multispectral remote sensing technology, that is, satellite imagery that can provide an effective and efficient alternative source of data for coral reef mapping (Hedley et al., 2005). Since multispectral satellite images with visible to near-infrared (VNIR) channels can be used to remotely characterize benthic habitats, such as coral reefs, seagrass beds, and macroalgae (Goodman et al., 2013), they have been widely used to map ones in optically shallow waters (Phinn et al., 2012; Wicaksono et al. 2019a). The specifications of multispectral satellite imagery continue to evolve, including increased spatial and spectral resolution and higher data acquisition capacity. Straightforward integration and access to multispectral satellite imagery enable its further development, in particular, applications for mapping, monitoring, and modeling for coral reef studies. Such advancement can contribute to increasing the accuracy of benthic habitats classification (Roelfsema et al., 2013).

Using different images can produce detailed information regarding the existence, diversity, and type of coral reefs, the composition of the geomorphological zone of coral reefs, benthic habitats, and coral life-form composition (Goodman et al., 2013). The level of detail of coral life-form information offers depends on the spatial resolution of the image 
used (Roelfsema et al., 2013). Therefore, each remote sensing image needs to be assessed for its capability to produce spatial information on a particular complexity of benthic habitats.

Several studies related to coral reefs use a classification scheme at the life-form level. For example, Wicaksono (2016) mapped 28 classes of coral life-forms around Kemujan Island, Zhang et al. (2013) used two classification schemes - namely group level (3 classes) and code level (12 classes), Phinn et al. (2012) mapped benthic habitat communities with 15 class schemes, and Roelfsema et al. (2013) also mapped coral reefs with a 20-class scheme. In some of these studies, the classification results do not cover all existing classes of coral reef life-forms, indicating limitations in the ability of the used images to discriminate between them. In addition, each coastal environment has different characteristics of coral reefs, meaning that any classification scheme and model developments must be first adjusted to them. Mapping coral reefs at the life-form level is one of the challenges several researchers remain to experience, mainly because the model designed for a coastal environment depends on the complexity of the coral reef composition and, thus, may very well be inapplicable to other coasts. Therefore, it is imperative that the role of multiresolution imagery in producing spatial information of coral reefs with various levels of detail be examined.

Therefore, this study aimed to evaluate the classification scheme of coral reef lifeform using images with different spatial resolutions on Parang Island, Karimunjawa Islands, Central Java. The multispectral satellite images used in this study are Planet Scope $(3 \mathrm{~m})$, PlanetScope resulted from the resampling process $(6 \mathrm{~m})$, and Sentinel-2A MSI (10m). Despite their easy access and fitting spatial resolution for mapping the individual variation of a class of coral reefs, these images are still rarely used in detailed benthic habitat studies, underlying their uses in this research. The study was designed to assess the classification scheme for coral reef life-form mapping using satellite images with different spatial resolutions on Parang Island, Karimunjawa Islands, Central Java Province (Figure 1). Parang is one of many islands in Indonesia that has highly diverse coastal ecosystems and is part of the Karimunjawa National Park Region. Compared with the other regions in Karimunjawa Islands, Parang is the least visited destination because it is located somewhat far from the main island of Karimunjawa. Low tourism activity has little to no effect on the condition of shallow water ecosystems on Parang Island. Accordingly, the coral reef cover on the island remains widely diverse and preserved. 


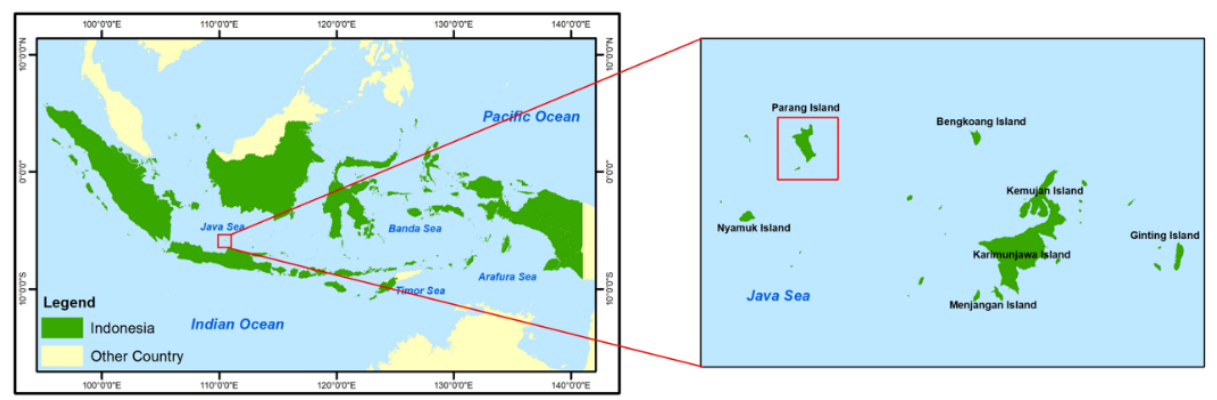

Figure 1. The location of Parang Island

\section{Methods}

\subsection{Image Preprocessing}

The multispectral images used in the research were PlanetScope (3m spatial resolution), PlanetScope Resampling (6m) recorded on April 30, 2018, and Sentinel-2A MSI (10m) on April 17, 2018. These images were corrected to minimize any biases caused by sensory and atmospheric conditions. In this study, the Sentinel-2A MSI image (10m) had the level 1C, and its Digital Number (DN) was converted to Top-Of-Atmosphere Reflectance (RTOA). Furthermore, this image was subjected to atmospheric, sunglint, and water column corrections. The PlanetScope image was the SR Product that had been corrected to Bottomof-Atmosphere Reflectance (RBOA) and subjected to water column correction. However, sunglint correction was not applied to the PlanetScope image because of a missed coregistration between visible and NIR bands, entirely removing the possibility of performing this correction.The specifications of both images can be seen in Table 1.

Table 1. Specification of the PlanetScope and Sentinel-2A MSI Images (Suhet, 2014; PlanetLabs, 2017)

\begin{tabular}{lcc}
\hline \multicolumn{1}{c}{ Image Spesification } & PlanetScope & Sentinel-2A MSI \\
\hline Spatial Resolution $(\mathrm{m})$ & 3 & 10 \\
Radiometric Resolution & $12-\mathrm{bit}$ & $12-\mathrm{bit}$ \\
Temporal Resolution & 1 day & $15-30$ days \\
Spectral Resolution $(\mu \mathrm{m})$ & - & - \\
Blue Band & $0.42-0.53$ & $0.45-0.52$ \\
Green Band & $0.50-0.59$ & $0.54-0.58$ \\
Red Band & $0.61-0.70$ & $0.65-0.68$ \\
near-infrared Band & $0.77-0.90$ & $0.78-0.90$ \\
\hline
\end{tabular}

Note : For the Sentinel-2A MSI image, only the bands used in the study are presented, including Visible - NIR bands 


\subsection{Atmospheric Correction}

Dark-Object Subtraction (DOS) was applied in this research because although it is one of the simplest atmospheric correction methods (Chavez, 1996 in Nazeer et al., 2014), it produces better results than other methods (Nazeer et al., 2014). DOS was carried out by analyzing the reflectance of dark objects in the image, and then the reflectance value was used to remove the atmospheric offset in the Sentinel-2A MSI image at RTOA level (Chavez, 1996 in Nazeer et al., 2014).

\subsection{Sunglint Correction}

Sunglint is a mirror-like specular reflection on the water surface that can produce noise in remote sensing applications for mapping in the optically shallow and optically deepwater regions. This study used a sunglint correction method by Hedley et al. (2005). Kay et al. (2009) compared various sunglint correction methods and showed that the Hedley et al. (2005) and Lyzenga et al. (2006) has the most constant results compared to other methods. Kay et al. (2009) also explained that the use of the Hedley et al. (2005) is more suitable for mapping benthic habitats, whereas for the correction method Lyzenga et al. (2006) is more suitable for use in bathymetry mapping.

\subsection{Water Column Correction}

The water column correction of sunglint-free images aimed to minimize changes in the spectral response of benthic habitats due to depth variations and the attenuation of electromagnetic energy in the water column (Maritorena, 1996). Lyzenga (1978) developed one of the most widely used algorithms for water column correction (Zhang et al., 2013) and is one of the simplest methods of water column correction (Zoffoli et al., 2014). This water column correction method utilizes the water column attenuation coefficient or ratio at two different wavelengths to eliminate the need for depth information and the water column attenuation coefficient at each wavelength (Lyzenga, 1978). The attenuation coefficient value for each band pairis presented in Table 2 .

Table 2. The ratio of water column attenuation coefficient value for each band pair

\begin{tabular}{lccc}
\hline \multirow{2}{*}{ Image } & \multicolumn{3}{c}{ Attenuation Coefficient (ki/kj) } \\
\cline { 2 - 4 } & DII 12 & DII 13 & DII 23 \\
\hline Planet (3 m) & 0.822 & 0.600 & 0.733 \\
Planet Resampling (6 m) & 0.854 & 0.601 & 0.710 \\
Sentinel 2 MSI (10 m) & 0.7195 & 0.518 & 0.722 \\
\hline
\end{tabular}




\subsection{Field Data Collection}

The field data were collected by the photo-transect method, which is very efficient in terms of cost, time, and energy (Roelfsema et al., 2006). Photos of benthic habitat were captured using an underwater camera by the surveyors while snorkeling in the optically shallow water. A GPS 78s was attached to the surveyor and set to the tracking mode to record coordinates at an interval of two seconds, with a UTM coordinate system in the $49 \mathrm{M}$ zone and the datum WGS84. The time indicators on both GPS and underwater cameras were synchronized (up to seconds) to geotag the taken benthic habitat photos with GPS coordinates accurately (Phinn et al., 2012). The compositions of benthic habitat and coral reef life-forms were obtained by interpreting the photo samples taken during the photo-transect survey in Coral Point Count Excel (CPCe) software.

\subsection{Image Classification}

Images that had been subjected to water column correction functioned as the input to the two-level classification process. In the first level, the major classifier was types of benthic habitats, namely coral reefs, seagrass, macroalgae, and bare substratum. In the second level, the minor classifier was the coral life-form, which was built according to the spatial resolution and segments of the used satellite images and based on the dominant life-form samples in each segment. In this level, the cross-classification of coral life-forms was carried out in each spatial resolution to assess whether the classification results were consistently accurate. After applying all classification schemes, the most suitable one for each satellite image was determined based on the highest accuracy produced (Table 4).

As an attempt to improve mapping accuracy, this study integrated two different approaches in the classification scheme, namely object-based and pixel-based (Ma et al., 2017). Several studies have proven that using the hybrid OBIA-Supervised classification method can improve mapping accuracy (Ma et al., 2017). The object-based approach adopted in this study was limited to the segmentation process in IDRISI Selva 17. Meanwhile, the pixel-based supervised classification involved the use of algorithms, such as Support Vector Machine (SVM) and Classification Tree Analysis (CTA), both of which possess the capacity to provide accurate classification of remote sensing images (Zambon et al., 2006; Wicaksono et al., 2019a). Compared with other algorithms in supervised classification, SVM can produce higher mapping accuracy than Maximum Likelihood (ML) and Artificial Neural Network (ANN) (Pal \& Mather, 2005; Wahidin et al., 2015). CTA can analyze large amounts of data with complex structures (Cappelli et al., 2002 in Zambon et al., 2006). In terms of 
classification, CTA algorithm has been reported to increase classification accuracy in several previous studies (Wicaksono et al., 2019b) and provide better results than ML.

In addition, the Object-Based Image Analysis (OBIA) relies on object characters or aspects to create classification, namely shape, texture, and relationship between objects (Mafanya et al., 2017). Although it can provide good mapping results, this study did not solely use OBIA because it lacks quantitative verification (Ma et al., 2017) and is highly dependent on the developed rules when applied to remote sensing data. Furthermore, designing and generating the rules requires adequate knowledge and experience, and even then, it is not easy to ascertain the error or truth of said rules. In addition, the development of OBIA rules strongly depends on the number of classes to be used in the classification. For instance, a high class diversity requires the developed rules to pay attention to each class, which is a lengthy process where repeated experiments are conducted to obtain a good rule for each step.

\subsection{Accuracy Assessment}

Accuracy assessment is an approach used to determine the extent to which a study result can be trusted. In the case of benthic habitat classification, its accuracy was assessed using a confusion matrix analysis. Samples for validation were used as reference data. Confusion matrix analysis offers information about user's accuracy (UA), producer's accuracy (PA), overall accuracy (OA), and kappa coefficient (Congalton \& Green, 2009). We determined the most appropriate classification scheme for each image based on the confusion matrix results.

\section{Results and Discussion}

\subsection{Field Data Collection}

The field survey of benthic habitat was carried out on April 17-19, 2018, and the location of the transects for data collection is presented in Figure 2. During this field survey, 1,658 samples were obtained. Based on the life-form variations at the study location, the dominant coral reef life-forms obtained by analyzing the photo samples were branching, stag horn, massive, pillar, foliage, encrusting, tabular, and dead coral; thereby, only these classes were used as the training areas for object classification. However, not all life forms can be used as a single class for training areas in the classification process, except for the frequently encountered and homogeneous ones. In some locations, the life-forms of coral reefs were not always homogeneous but consisted of multiple types. 


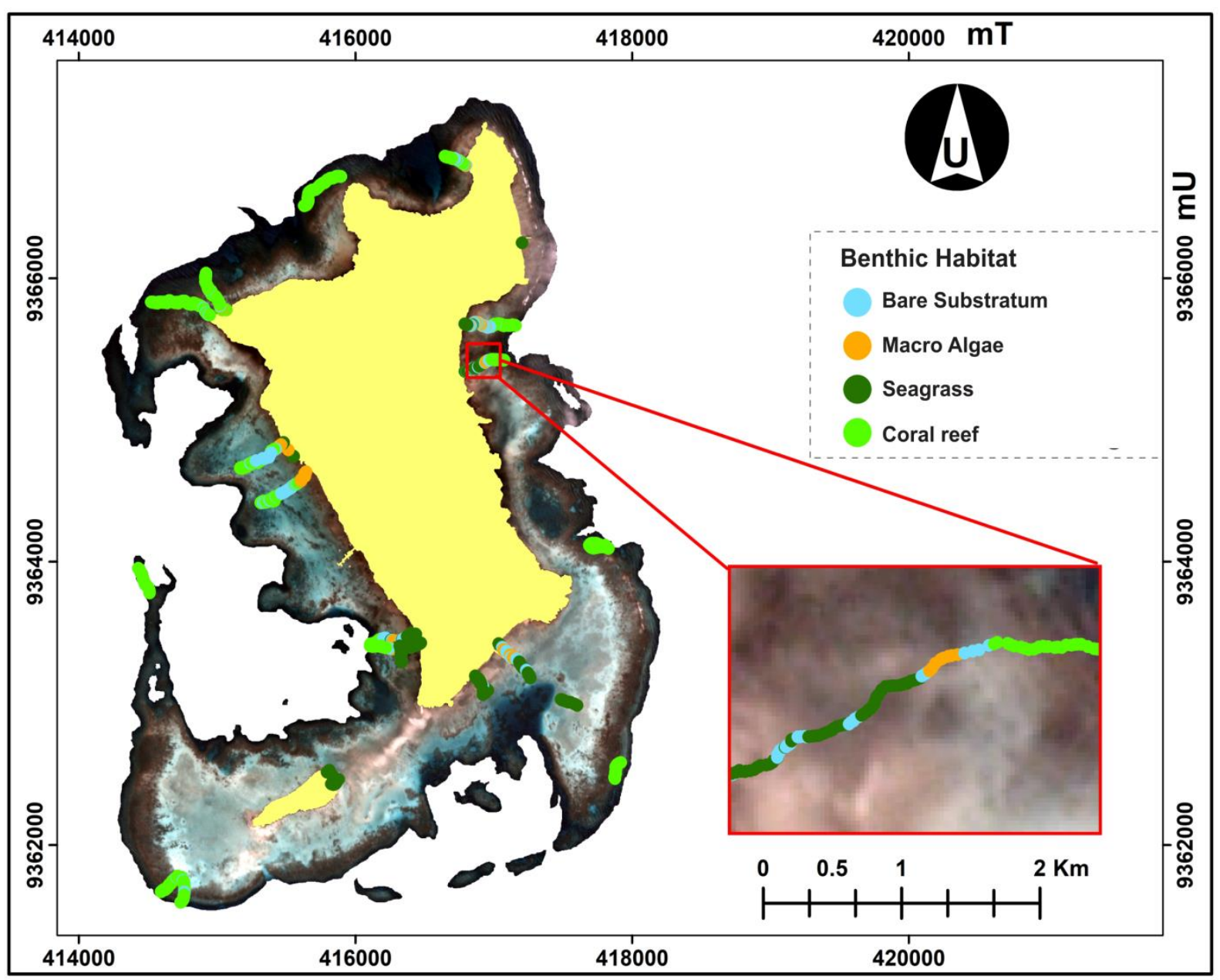

Figure 2. Field data collection using the photo-transect method

\subsection{Coral Reef Life-Forms Classification Scheme}

The classification scheme of coral reef life-forms was obtained through the dominance analysis of each segment in the three satellite images (Phinn et al., 2012). However, should the existing sample consist of different classes and has the same percentage, it is classified based on the number of classes in the image segment (mixed class). Based on Table 3, the classification schemes of coral reef life-forms, built from each image, have different numbers of classes. 
Table 3. The classification schemes of benthic habitats and coral reef life-forms at each spatial resolution

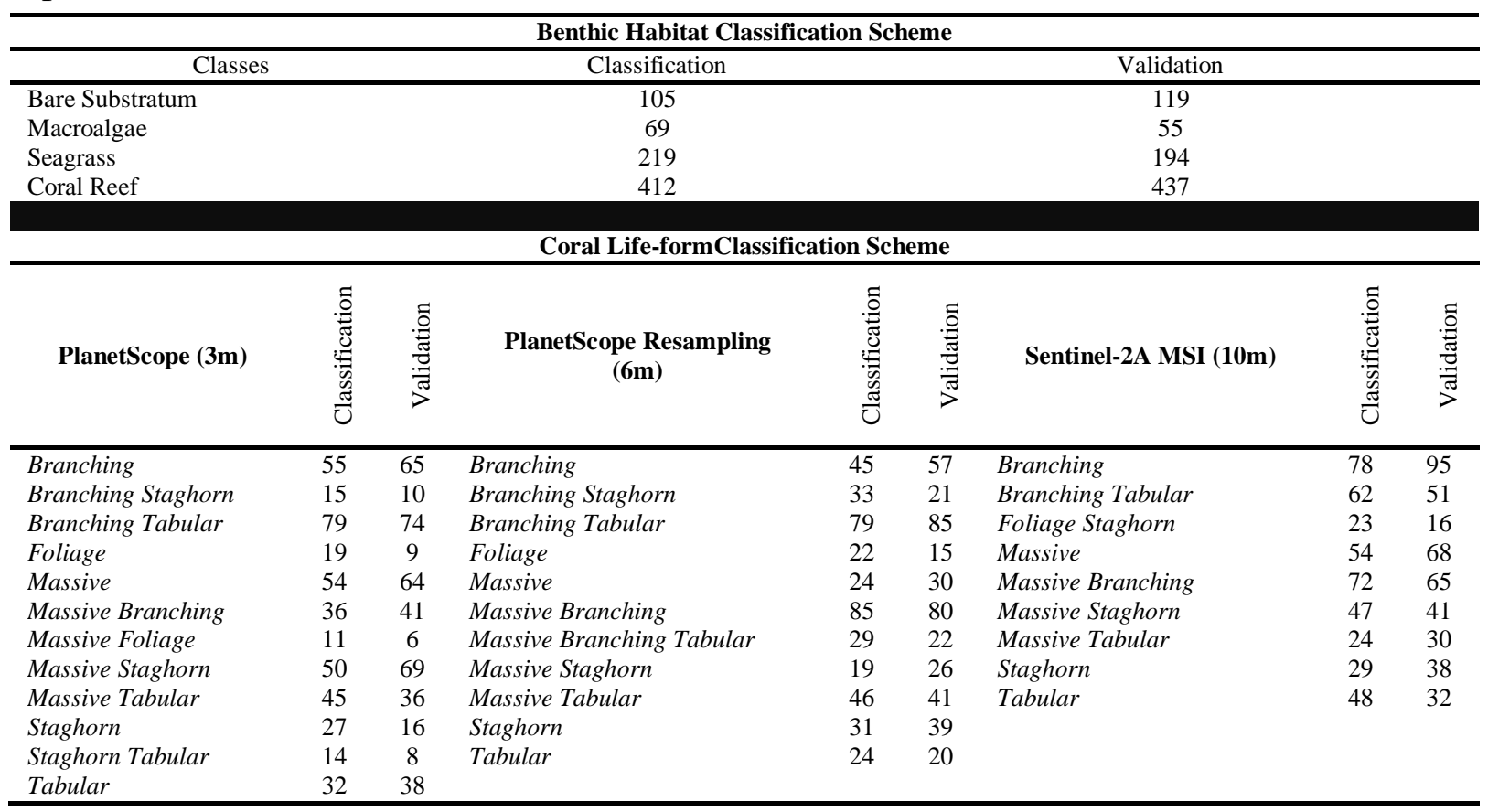

\subsection{Benthic Habitat Mapping}

Benthic habitat mapping sought to obtain the best spatial distribution of coral reef (coral reef mask image), which was used as a basis for the classification of coral reef lifeforms. In the classification process, the benthic habitat was a major classifier that defined four types of habitat, namely coral reef, seagrass, macroalgae, and bare substratum (Figure 3). The classification scheme of benthic habitat has an OA of 57-63\% (Table 4). PlanetScope Resampling (6m) images produced the highest accuracy, with an OA of $63.10 \%$ and a kappa coefficient of 0.38 , which was obtained using the CTA classification algorithm and was higher than using the SVM algorithm. The accuracies of benthic habitat mapping using the CTA and SVM algorithms differed by approximately 5\%. The overall accuracies of benthic habitat classification from different algorithms and images are compared in Table 4.

Table 4. Summary of the assessment of benthic habitat mapping accuracy

\begin{tabular}{|c|c|c|c|c|}
\hline \multirow{2}{*}{ Image } & \multicolumn{2}{|c|}{ CTA } & \multicolumn{2}{|c|}{ SVM } \\
\hline & OA (\%) & Kappa & OA (\%) & Kappa \\
\hline PlanetScope $(3 \mathrm{~m})$ & 57.26 & 0.49 & 61.86 & 0.32 \\
\hline PlanetScope Resampling (6 m) & $63.10^{*}$ & 0.38 & 58.75 & 0.22 \\
\hline Sentinel-2A MSI (10 m) & 57.26 & 0.16 & 57.14 & 0.08 \\
\hline
\end{tabular}

Note : *indicates the highest overall accuracy

Judging from the overall classification schemes of benthic habitat, CTA algorithm produced a spatial distribution of benthic habitats more consistently-in which all types of 
habitats were classified - and with a higher OA for each satellite image than SVM algorithm, even though the accuracy difference is merely 5\%. SVM algorithmprovided less accurate results because several types of benthic habitats, such as macroalgae and sand were not applicable for classification. Another reason was inter-class misclassification; for example, sand was misclassified into seagrass and macroalgae. Sand has a spectral response that is similar to low seagrass and macroalgae due to the contribution of sand reflectance as the substrate of seagrass and macroalgae (Wicaksono, 2016). Also, coral reefs were misclassified into macroalgae because both objects have comparable spectral response due to similar pigmentation (Hochberg \& Atkinson, 2000; Wicaksono, 2016).

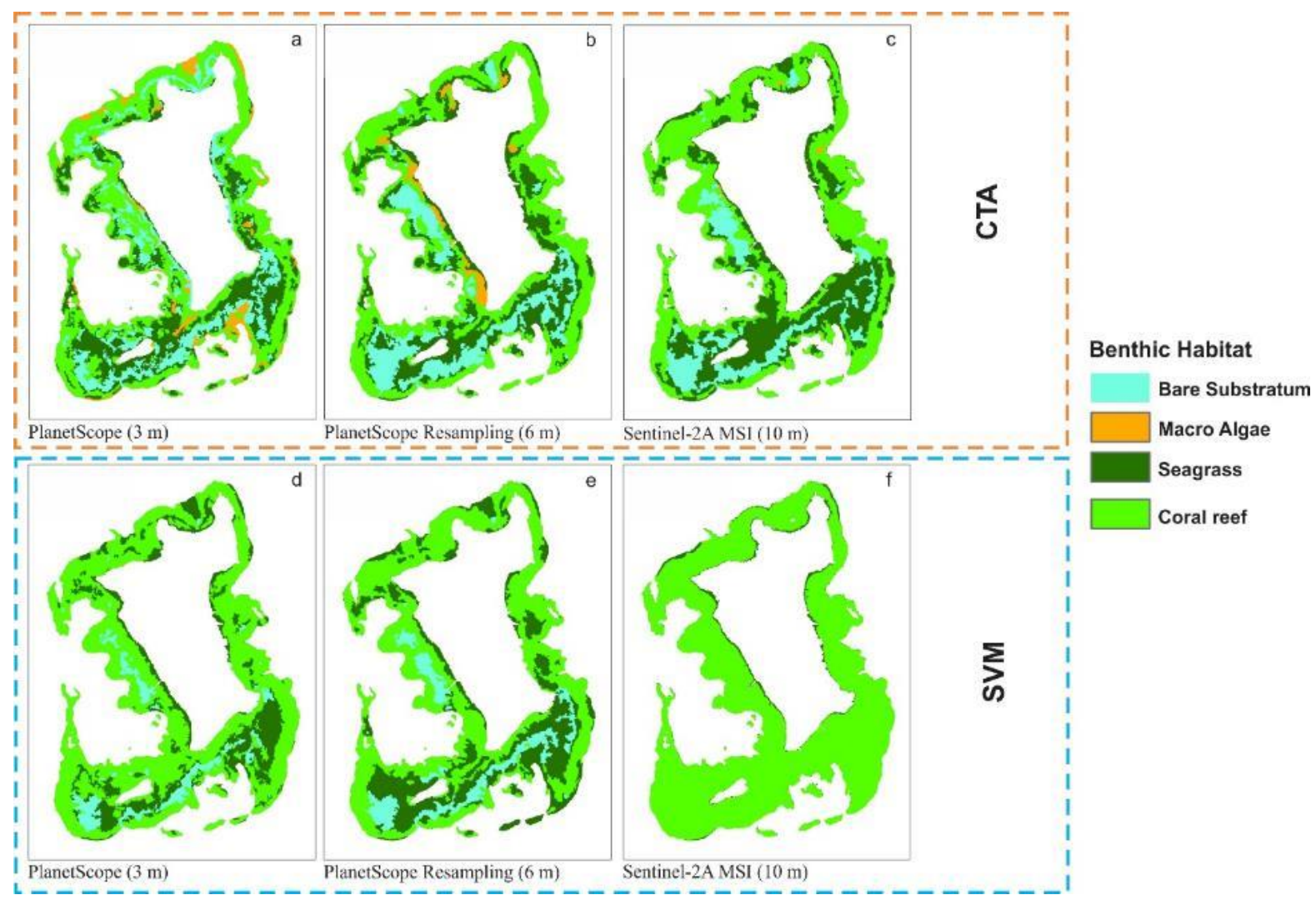

Figure 3. A comparison of benthic habitat classification resulted from different classification algorithms and satellite images

Table 5. Comparison of user's accuracy (UA) and producer's accuracy (PA) of coral reef classes

\begin{tabular}{|c|c|c|c|c|c|c|}
\hline \multirow[b]{2}{*}{ Image } & \multicolumn{3}{|c|}{ CTA-based } & \multicolumn{3}{|c|}{ SVM-based } \\
\hline & PA (\%) & UA (\%) & $\begin{array}{c}\text { Resulted } \\
\text { Accuracy } \\
(\%)\end{array}$ & $\begin{array}{l}\text { PA } \\
(\%)\end{array}$ & $\begin{array}{l}\text { UA } \\
(\%)\end{array}$ & $\begin{array}{c}\text { Resulted } \\
\text { Accuracy } \\
(\%)\end{array}$ \\
\hline PlanetScope (3 m) & 80.55 & 73.79 & 59.43 & 89.93 & 59.10 & 53.14 \\
\hline $\begin{array}{l}\text { PlanetScope resampling } \\
(6 \mathrm{~m})\end{array}$ & 83.07 & 73.19 & 60.79 & 87.87 & 61.84 & 54.33 \\
\hline Sentinel-2A MSI $(10 \mathrm{~m})$ & 85.35 & 68.69 & 58.62 & 99.77 & 56.26 & 56.13 \\
\hline
\end{tabular}


Based on the overall results of the benthic habitat classification, the individual accuracy (UA and PA) of the coral reef life-forms classification ranged from 56 - 99\% (Table 5). The CTA-based classification from PlanetScope $(3 \mathrm{~m})$ was used in the masking of coral reef images or to exclude non-coral reef pixels in the mapping. Although the OA of the CTAbased classification from PlanetScope $(3 \mathrm{~m})$ image was slightly lower than PlanetScope Resampling (6m), the spatial resolution was higher than PlanetScope Resampling $(6 \mathrm{~m})$ and Sentinel-2A MSI (10m), and producing more precise coral reef masking delineation.

\subsection{Coral Reef Life-Form Mapping}

The coral reef life-forms were mapped by applying the classification schemes built on each satellite image (see Table 3). The coral reef life-form classification (Figure 4) with the highest OA (60.78\%) was obtained from Sentinel-2A MSI image using CTA algorithm and the $10 \mathrm{~m}$ scheme, and then followed by PlanetScope (48.39\%), and PlanetScope Resampling (40.83\%) (Table 6). Although the CTA algorithm could consistently produce maps of coral reef life-forms with higher OA than SVM, the generated classification was relatively low, in particular, because of a large number of misclassifications as a result of similar statistics between the classes of coral reef life-forms. For this reason, both CTA and SVM classification algorithms could not separate one life-form from another straightforwardly.

The coral reef life-form classifications built from the three satellite images showed different spatial distribution (Figure 4). PlanetScope (3m) and Sentinel-2A MSI (10m) images presented similar distributions of life-forms in some locations, and different spread patterns are found in some others. This similarity indicates consistency in the classification results produced using different images. The spatial distribution of several coral reef lifeforms corresponds to the theory proposed by English et al. (1994), that is, coral reef lifeforms spread following the locations of optimal environmental conditions for their growth. The opposite is true for the classification scheme built from the PlanetScope Resampling $(6 \mathrm{~m})$, which only has one class, i.e., the tabular branching that dominated the study area. It is caused by the effects of the image pixel resampling process from $3 \mathrm{~m}$ to $6 \mathrm{~m}$. 


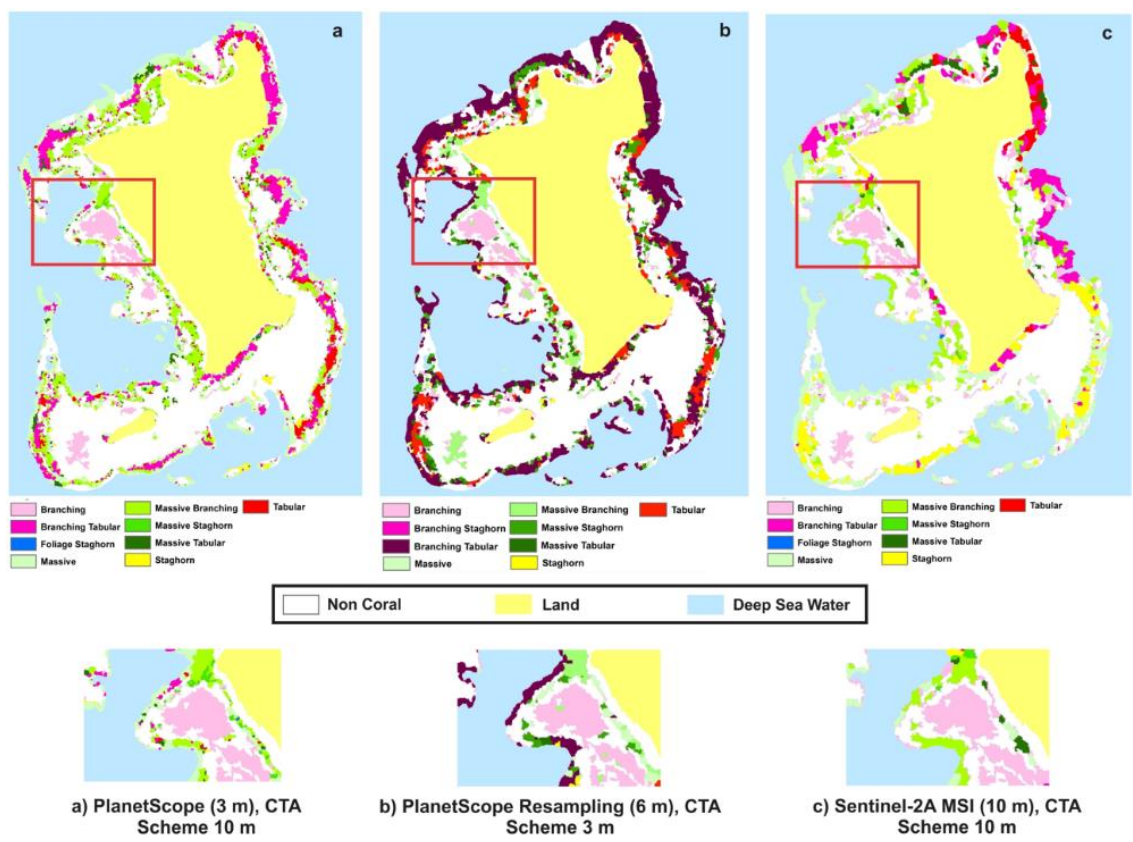

Figure 4. Comparison of coral reef life-form maps with the highest OA

Table 6. Comparison of the overall accuracies of the resulted coral reef life-form classifications

\begin{tabular}{|c|c|c|c|c|c|c|}
\hline \multirow{2}{*}{ Images } & \multicolumn{2}{|c|}{ 3m Scheme } & \multicolumn{2}{|c|}{ 6m Scheme } & \multicolumn{2}{|c|}{ 10m Scheme } \\
\hline & CTA $(\%)$ & SVM (\%) & CTA $(\%)$ & SVM (\%) & CTA (\%) & SVM (\%) \\
\hline PlanetScope (3m) & 38.76 & 30.05 & 35.32 & 27.52 & 48.39 & 39.45 \\
\hline $\begin{array}{l}\text { PlanetScope resampling } \\
\qquad(6 \mathrm{~m})\end{array}$ & 40.83 & 31.65 & 39.91 & 27.52 & 36.01 & 40.60 \\
\hline Sentinel-2A MSI (10m) & 39.91 & 26.38 & 46.56 & 30.28 & 60.78 & 42.20 \\
\hline
\end{tabular}

The resampling process generalizes pixel values by considering the surrounding pixels (i.e., mean values). Therefore, variations in the pixel values of the analyzed objects canbe very similar, and as a result, pixels that should be classified as different objects are categorized as the same object. Accordingly, the image resampling process is not recommended for addressing issues of unavailable images with a particular spatial resolution due to its poor results. Different distributions of coral reef life-forms obtained from the multiresolution images were potentially caused by the size of the spatial resolution itself. As evidence, different spatial resolutions have different spectral responses from the object composition. Accordingly, the distributions of coral reef life-forms are different from one satelliteimage to another (Figure 4 and Table 7). The classification results of the satellite image with $6 \mathrm{~m}$ spatial resolution were not included in the comparison because the 
generalization ofthe spatial resolution was believed to produce less representative distribution.

Table 7. The classification schemes of coral reef life-forms

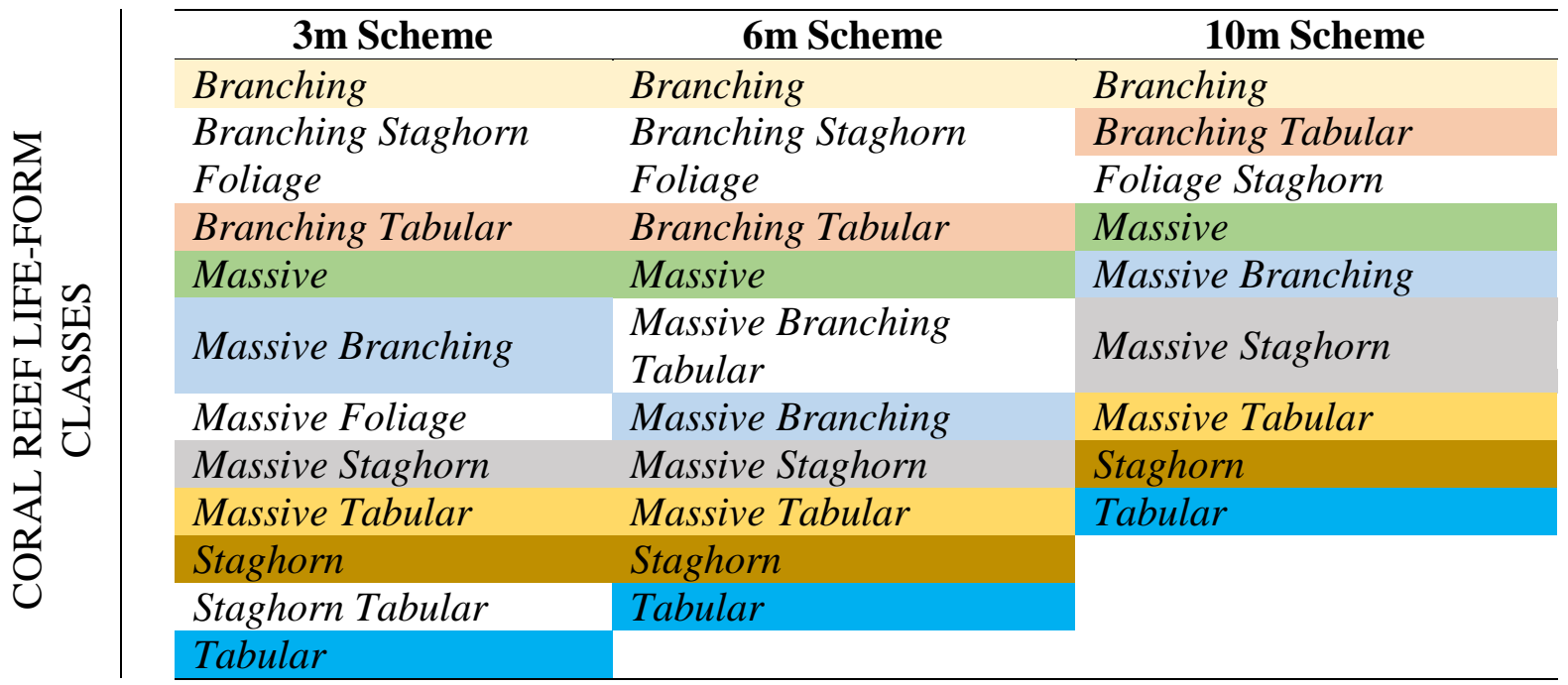

Based on the highest accuracy of the maps produced from each satellite image and classification scheme (Table 6), the coral reef life-forms captured in PlanetScope $(3 \mathrm{~m})$ and Sentinel-2A MSI (10m) were best mapped using the $10 \mathrm{~m}$ scheme. Unlike in the two satellite images, the coral reef life-forms featured in PlanetScope Resampling $(6 \mathrm{~m})$ were best mapped using the $3 \mathrm{~m}$ scheme. However, not all life-forms were applicable for classification. Eight classes of coral reef life-forms were consistently classified in all images and schemes, namely branching, tabular branching, massive, massive branching, massive staghorn, massive tabular, staghorn, and tabular. As seen in Tables 8, 9, and 10, each life-form was properly classified for each image with high UA and PA. Nevertheless, overestimate and underestimate could occur. Therefore, the classes above can be used in the classification schemes of coral reef life-forms in various images (Table 7).

Table 8. Confusion matrix of PlanetScope $(3 \mathrm{~m})$ using the $10 \mathrm{~m}$ scheme based on the CTAbased classification result

\begin{tabular}{|c|c|c|c|c|c|c|c|c|c|c|c|}
\hline \multirow{2}{*}{ Classes } & \multicolumn{11}{|c|}{ References } \\
\hline & 1 & 2 & 3 & 4 & 5 & 6 & 7 & 8 & 9 & Total & UA \% \\
\hline 1 & 62 & 0 & 7 & 22 & 13 & 12 & 0 & 2 & 0 & 118 & 52.54 \\
\hline 2 & 3 & 37 & 2 & 3 & 6 & 0 & 7 & 6 & 10 & 74 & 50.00 \\
\hline 3 & 0 & 0 & 0 & 0 & 0 & 1 & 0 & 0 & 0 & 1 & 0.00 \\
\hline 4 & 18 & 4 & 3 & 43 & 1 & 7 & 7 & 19 & 1 & 103 & 41.75 \\
\hline 5 & 11 & 0 & 0 & 0 & 43 & 17 & 1 & 8 & 11 & 91 & 47.25 \\
\hline 6 & 0 & 2 & 0 & 0 & 0 & 4 & 0 & 0 & 0 & 6 & 66.67 \\
\hline
\end{tabular}


Wahyu Lazuardi \& Pramaditya Wicaksono/ Geosfera Indonesia 6 (3), 2021, 377-397

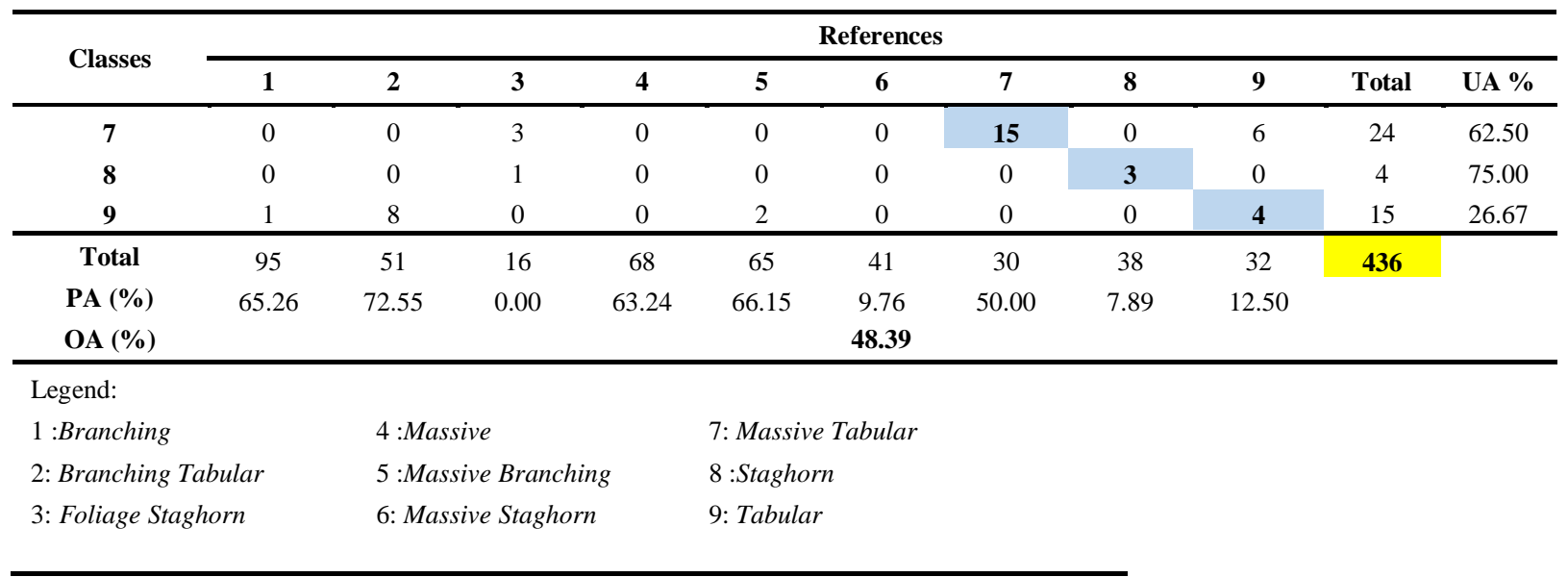

Table 9. Confusion matrix of PlanetScope $(3 \mathrm{~m})$ using the $3 \mathrm{~m}$ scheme based on the CTAbased classification result

\begin{tabular}{|c|c|c|c|c|c|c|c|c|c|c|c|c|c|c|}
\hline \multirow{2}{*}{ Class } & \multicolumn{14}{|c|}{ References } \\
\hline & 1 & 2 & 3 & 4 & 5 & 6 & 7 & 8 & 9 & 10 & 11 & 12 & Total & UA $(\%)$ \\
\hline 1 & 46 & 5 & 6 & 0 & 14 & 19 & 0 & 23 & 0 & 0 & 8 & 4 & 125 & 36.80 \\
\hline 2 & 0 & $\mathbf{0}$ & 0 & 2 & 0 & 0 & 0 & 0 & 0 & 0 & 0 & 0 & 2 & 0.00 \\
\hline 3 & 16 & 1 & 48 & 1 & 20 & 1 & 6 & 13 & 6 & 9 & 0 & 11 & 132 & 36.36 \\
\hline 5 & 0 & 0 & 1 & 1 & 16 & 0 & 0 & 0 & 1 & 3 & 0 & 0 & 22 & 72.73 \\
\hline 6 & 0 & 4 & 0 & 5 & 3 & 21 & 0 & 3 & 0 & 0 & 0 & 0 & 36 & 58.33 \\
\hline 8 & 2 & 0 & 14 & 0 & 4 & 0 & 0 & 25 & 26 & 0 & 0 & 8 & 79 & 31.65 \\
\hline 9 & 0 & 0 & 0 & 0 & 0 & 0 & 0 & 0 & 3 & 0 & 0 & 0 & 3 & 100 \\
\hline 10 & 0 & 0 & 0 & 0 & 0 & 0 & 0 & 0 & 0 & 4 & 0 & 0 & 4 & 100 \\
\hline 12 & 1 & 0 & 5 & 0 & 7 & 0 & 0 & 5 & 0 & 0 & 0 & 15 & 33 & 45.45 \\
\hline Total & 65 & 10 & 74 & 9 & 64 & 41 & 6 & 69 & 36 & 16 & 8 & 38 & 436 & \\
\hline PA $(\%)$ & 70.77 & 0 & 64.86 & 0 & 25.00 & 51.22 & 0 & 36.23 & 8.33 & 25.00 & 0 & 39.47 & & \\
\hline OA $(\%)$ & & & & & & & & 41.00 & & & & & & \\
\hline \multicolumn{15}{|l|}{ Legend: } \\
\hline \multicolumn{2}{|l|}{1 :Branching } & \multicolumn{4}{|c|}{4 :Foliage } & \multicolumn{4}{|c|}{ 7: Massive Foliage } & \multicolumn{3}{|c|}{10 :Staghorn } & & \\
\hline \multicolumn{2}{|c|}{ 2: Branching Staghorn } & \multicolumn{4}{|c|}{5 :Massive } & \multicolumn{4}{|c|}{8 :Massive Staghorn } & \multicolumn{5}{|c|}{11 :Staghorn Tabular } \\
\hline \multicolumn{2}{|c|}{ 3: Branching Tabular } & \multicolumn{4}{|c|}{ 6: Massive Branching } & \multicolumn{4}{|c|}{ 9: Massive Tabular } & \multicolumn{3}{|c|}{12 :Tabular } & & \\
\hline
\end{tabular}

Table 10. Confusion matrix of Sentinel-2A MSI $(10 \mathrm{~m})$ using the $10 \mathrm{~m}$ scheme based on the CTA-based classification result

\begin{tabular}{|c|c|c|c|c|c|c|c|c|c|c|c|}
\hline \multirow{2}{*}{ Class } & \multicolumn{11}{|c|}{ References } \\
\hline & 1 & 2 & 3 & 4 & 5 & 6 & 7 & 8 & 9 & Total & UA \% \\
\hline 1 & 83 & 0 & 5 & 28 & 17 & 20 & 0 & 3 & 0 & 156 & 53.21 \\
\hline 2 & 7 & 46 & 0 & 12 & 2 & 0 & 0 & 0 & 14 & 81 & 56.79 \\
\hline 3 & 0 & 0 & 11 & 0 & 0 & 0 & 0 & 0 & 0 & 11 & 100 \\
\hline 4 & 0 & 5 & 0 & 28 & 8 & 0 & 0 & 5 & 3 & 49 & 57.14 \\
\hline 5 & 2 & 0 & 0 & 0 & 38 & 6 & 17 & 0 & 5 & 68 & 55.88 \\
\hline 6 & 0 & 0 & 0 & 0 & 0 & 10 & 0 & 0 & 0 & 10 & 100 \\
\hline 7 & 0 & 0 & 0 & 0 & 0 & 5 & 13 & 0 & 0 & 18 & 72.22 \\
\hline 8 & 3 & 0 & 0 & 0 & 0 & 0 & 0 & 30 & 4 & 37 & 81.08 \\
\hline 9 & 0 & 0 & 0 & 0 & 0 & 0 & 0 & 0 & 6 & 6 & 100 \\
\hline Total & 95 & 51 & 16 & 68 & 65 & 41 & 30 & 38 & 32 & 436 & \\
\hline PA $(\%)$ & 87.36 & 90.19 & 68.75 & 41.17 & 58.46 & 24.39 & 43.33 & 78.94 & 18.75 & & \\
\hline OA (\%) & & & & & & 60.78 & & & & & \\
\hline
\end{tabular}




\begin{tabular}{|c|c|c|}
\hline \multicolumn{3}{|l|}{ Legend: } \\
\hline 1: Branching & 4: Massive & 7: Massive Tabular \\
\hline 2: Branching Tabular & 5: Massive Branching & 8: Staghorn \\
\hline 3: Foliage Staghorn & 6: Massive Staghorn & 9: Tabular \\
\hline
\end{tabular}

The classification schemes of coral reef life-forms are constructed from three satellite images with different spatial resolutions. Three schemes of classification with varying numbers of classes have been built in this study (Table 3). Some classes in these schemes depict similar types of coral reef life-forms, such as branching, tabular branching, massive, massive branching, massive staghorn, massive tabular, staghorn, and tabular. Nevertheless, some classes are only found in a particular scheme because their generation depends on the uniquely formed image segments (Phinn et al., 2012). Each satellite images of which indeed produces classification schemes with different suitability for coral reef life-form mapping. Here, suitability is defined by the highest OA in each image. Table 6 shows that PlanetScope (3m) and Sentinel-2A MSI (10m) images are suitable using the $10 \mathrm{~m}$ scheme, whereas PlanetScope Resampling (6m) image using the $3 \mathrm{~m}$ scheme.

PlanetScope $(3 \mathrm{~m})$ is not suitable using the $3 \mathrm{~m}$ and $6 \mathrm{~m}$ schemes because the statistical value of each pixel in its segment is too precise. Consequently, the same objects have varying pixel values, causing too many misclassifications (Purkis, 2018). Meanwhile, the 10m scheme produces higher accuracy than the $3 \mathrm{~m}$ and $6 \mathrm{~m}$ schemes because the classification wasbuilt from images with a lower spatial resolution (general information) (Zhang et al., 2013). As a result, variations of pixel values in a segment are considered one life-form class so that the said segment can be classified according to the input sample (Phinn et al., 2012).

PlanetScope Resampling $(6 \mathrm{~m})$ is more suitable using the $3 \mathrm{~m}$ scheme because the generalization during the spatial resolution resampling results in similarities. In this case, the $10 \mathrm{~m}$ scheme is not suitable for use because the effect of generalization increases the homogeneity of image statistics to PlanetScope $(3 \mathrm{~m})$ instead of the Sentinel-2A MSI $(10 \mathrm{~m})$, even though the level of precision is different. Several studies have shown that the higher the number of classes used, the lower the accuracy (Wicaksono, 2016; Wicaksono et al., 2019a). However, the contrary is true for this study, where the findings correspond to Zhang et al. (2013) instead. They used two classification schemes consisting of group level (3 classes) and code level (12 classes) and found that the latter produces a higher accuracy (86.7\%) than the former $(84.3 \%)$. 
Sentinel-2A MSI $(10 \mathrm{~m})$ is more suitable using the $10 \mathrm{~m}$ scheme because it produces classes that are more general than the $3 \mathrm{~m}$ and $6 \mathrm{~m}$ schemes. The classified types of coral reef life-forms in the Sentinel-2A MSI image will not be optimal if the used classification scheme is built from images with more detailed spatial resolutions. For example, if two different classes from the $3 \mathrm{~m}$ or $6 \mathrm{~m}$ scheme occupy a segment, one that appears dominantly will be selected over the other, creating low accuracy. On the contrary, if the used classification scheme is built from the same image, each sample of each class undoubtedly corresponds to the previously formed segments. Consequently, each segment can be classified more accordingly to the input sample, leading to a higher OA than the other schemes.

The selected satellite images can map the life-forms of coral reefs with overall accuracies of $48.39 \%$ (PlanetScope 3m, CTA, 10m scheme), 40.83\% (PlanetScope Resampling 6m, CTA, 3m scheme), and 60.78\% (Sentinel-2A MSI $10 \mathrm{~m}$, CTA, 10m scheme). Multiresolution images produce classifications with multilevel accuracy (Mumby \& Edward, 2002), and satellite imagery with a more detailed spatial resolution can yield higher accuracy (Goodman et al., 2013). However, the highest accuracy in this study is shown by images with a lower spatial resolution $(10 \mathrm{~m})$ because the more detailed ones, i.e., $3 \mathrm{~m}$ and $6 \mathrm{~m}$, cannot represent a community or a dominant class of coral reef life-forms. In addition, Sentinel 2 MSI also has a fairly consistent image quality (Hedley et al., 2018; Wicaksono et al., 2021) compared with PlanetScope, whose pixels between scenes are inconsistent and SNR is of poor quality (Wicaksono \& Lazuardi, 2018). Based on the percentage, the coral reef life-forms are covered with diverse objects, meaning that the resulted spectral response is a function of various classes.

Sentinel-2A MSI (10m) has successfully produced the highest accuracy, followed by PlanetScope $(3 \mathrm{~m})$ and PlanetScope Resampling $(6 \mathrm{~m})$. The resampling process generalizes the spectral response value of the image, and the results are less suitable for representing a variety of objects because the spectral response is the mean value of the surrounding pixels. In other terms, the spectral response produced in the resampling process shows similarities among different objects. These numerous cases of misclassifications contribute to the overall accuracy of PlanetScope Resampling $(6 \mathrm{~m})$, which is lower than that of PlanetScope $(3 \mathrm{~m})$. Furthermore, the difference in OA can be caused by the quality of the used satellite image. For instance, despite the high spatial resolution, the pixel sharpness of the PlanetScope $(3 \mathrm{~m})$ image is still lower than Sentinel-2A MSI (10m) that has a lower resolution. Furthermore, the results obtained from the three satellite images have different UA and PA. 
When the accuracies are compared, the CTA algorithm evidently produces the best and most consistent accuracy (Zambon et al., 2006) of life-form classification (Wahidin et al., 2015). It allows the proper classification of coral reef life-forms in each of the three satellite images. The CTA and SVM algorithms produce different OA by averagely $12 \%$, which, in terms of OA, is significant. The SVM algorithm provides a low accuracy because not all coral reef life-forms are classified. On the contrary, the CTA algorithm has a better capability to classify coral reef life-forms, especially in schemes that create a large number of classes. Although the accuracy derived in this study is merely $40-60 \%$, the results are in line with previous similar studies (Phinn et al., 2012; Roelfsema et al., 2013; Wahidin et al., 2015; Wicaksono, 2016). Although Sentinel-2A MSI (10m) can create a coral reef life-form map with higher accuracy than other images, the level of information obtained from it is somewhat general. Meanwhile, PlanetScope $(3 \mathrm{~m})$ has lower accuracy, but it can map coral reef life-forms in more detail and involve precise information compared with Sentinel-2A MSI (10m).

\section{Conclusion}

Our results have shown that both PlanetScope (3m) and Sentinel-2A MSI (10m) can be used to map coral reef with higher complexity. This finding indicates that multiresolution images can be used to produce complex coral reef life-form maps with different levels of information details. In our case, the classification scheme on multiresolution images shows that the coral reef life-forms in PlanetScope and Sentinel-2A MSI images can be mapped using the $10 \mathrm{~m}$ scheme, whereas the ones in PlanetScope Resampling $(6 \mathrm{~m})$ image are mapped according to the $3 \mathrm{~m}$ scheme. Parang Island has eight types of coral reef life-forms that can be classified consistently in each satellite image, namely branching, branching staghorn, tabular branching, massive branching, massive staghorn, massive tabular, staghorn, and tabular. Based on the statistical analysis and accuracy assessment, the maximum overall accuracies of the coral reef life-form maps produced from PlanetScope (3m), PlanetScope Resampling (6m), and Sentinel-2A MSI (10m) images are 48.39\% (10m scheme), 40.83\% (3m scheme), and $60.78 \%$ (10m scheme), respectively. The accuracy obtained in our work can be used as a reference for future works of coral reef life-forms mapping. Possibly, variations in accuracy is expected since coral reefs life-forms may vary significantly between areas. Finally, the future availability of detailed coral reef map at regular basis will be beneficial to assist coastal manager in determining and monitoring the effective action to managed their area sustainably. 


\section{Conflict of interest}

There is no conflict of interest with any financial, personal, or other relationships with other people or organizations related to the material discussed in the article.

\section{Acknowledgements}

This research is funded by "Direktorat Riset dan Pengabdian Masyarakat - Direktorat Jenderal Penguatan Riset dan Pengembangan - Kementerian Riset, Teknologi, dan Pendidikan Tinggi Republik Indonesia” via Penelitian Dasar Unggulan Perguruan Tinggi PDUPT Scheme Grant Number 153/UN1/DITLIT/DIT-LIT/LT/2018.

\section{References}

Congalton, R. G., \& Green, K. (2009). Assesing the Accuracy of Remotely Sensed Data : Principles and Practices Second Edition. USA: CRC Press Inc.

Dudgeon, S., Aronson, R., Bruno, J., \& Precht, W. (2010). Phase shifts and stable states on coral reefs. Marine Ecology Progress Series, 413, 201-216. https://doi/10.3354/meps08751.

English, S., Wilkinson, C., \& Baker, V. (1994). Survey Manual for Tropical Marine Research. Townsville: ASEAN-Australia Marine Science Project. Canberra: Australian Institute of Marine Science.

Giyanto, Abrar, M., Hadi, T. A., Budiyanto, A., Hafizt, M., Salatalohy, A., \& Iswari, M. Y. (2017). Status Terumbu Karang Indonesia. Jakarta: Pusat Penelitian Oseanografi LIPI.

Goodman, J. A., Purkis, S. J., \& Phinn, S. R. (2013). Coral Reef Remote Sensing: A Guide for Mapping, Monitoring and Management. New York: London: Springer.

Green, E. P., Mumby, P. J., Edwards, A. J., \& Clark, C. D. (2000). Remote Sensing handbook for Tropical Coastal Management. Paris: UNESCO.

Hedley, J. D., Harborne, A. R., \& Mumby, P. J. (2005). Technical note : Simple and robust removal of sun glint for mapping shallow-water benthos. International Journal of Remote Sensing, 26(10), 2107-2112. https://doi.org/10.1080/01431160500034086.

Hedley, J. D., Roelfsema, C., Brando, V., Giardino, C., Kutser, T., Phinn, S., ... Koetz, B. (2018). Coral reef applications of Sentinel-2: Coverage, characteristics, bathymetry and benthic mapping with comparison to Landsat 8. Remote Sensing of Environment, 216, 598-614. https://doi.org/10.1016/j.rse.2018.07.014.

Hochberg, E. J., \& Atkinson, M. J. (2000). Spectral discrimination of coral reef benthic communities. Coral Reefs, 19(2), 164-171. https://doi.org/10.1007/s003380000087.

Hoegh-Guldberg, O., Mumby, P. J., Hooten, A. J., Steneck, R. S., Greenfield, P., Gomez, E., ... \& Hatziolos, M. E. (2007). Coral reefs under rapid climate change and ocean acidification. science, 318(5857),1737-1742. htpps://doi.org/10.1126/science.1152509 
Kay, S., Hedley, J. D., \& Lavender, S. (2009). Sun glint correction of high and low spatial resolution images of aquatic scenes: A review of methods for visible and near-infrared wavelengths. Remote Sensing, 1(4), 697-730. https://doi.org/10.3390/rs1040697.

Larkum, A., Orth, R., \& Duarte, C. (2006). Seagrasses: Biology, ecology and conservation. Dodrecht: Springer.

Lyzenga, D. R. (1978). Passive remote sensing techniques for mapping water depth and bottom features. Applied optics, 17(3), 379-383.

Lyzenga, D. R., Malinas, N. P., \& Tanis, F. J. (2006). Multispectral bathymetry using a simple physically based algorithm. IEEE Transactions on Geoscience and Remote Sensing, 44(8), 2251-2259. https://doi.org/10.1109/TGRS.2006.872909.

Ma, L., Li, M., Ma, X., Cheng, L., Du, P., \& Liu, Y. (2017). A review of supervised objectbased land-cover image classification. ISPRS Journal of Photogrammetry and Remote Sensing, 130, 277-293. https://doi.org/10.1016/j.isprsjprs.2017.06.001.

Madduppa, H. H., Santoso, P., Subhan, B., Anggoro, A. W., Cahyani, N. K. D., \& Arafat, D. (2019). Different species, life form, and complexity of dead coral head affect the species diversity and density of decapods. Paper presented at the IOP Conference Series: Earth and Environmental Science, 278(1). https://doi.org/10.1088/1755$1315 / 278 / 1 / 012042$.

Mafanya, M., Tsele, P., Botai, J., Manyama, P., Swart, B., \& Monate, T. (2017). Evaluating pixel and object based image classification techniques for mapping plant invasions from UAV derived aerial imagery: Harrisia pomanensis as a case study. ISPRS Journal of Photogrammetry and Remote Sensing, 129, 1-11. https://doi.org/10.1016/j.isprsjprs.2017.04.009.

Maritorena, S. (1996). Remote sensing of the water attenuation in coral reefs: a case study in French Polynesia. International Journal of Remote Sensing, 17(1), 155-166. https://doi.org/10.1080/01431169608948992.

Mumby, P. J., \& Edwards, A. J. (2002). Mapping marine environments with IKONOS imagery: enhanced spatial resolution can deliver greater thematic accuracy. Remote sensing of environment, 82(2-3), 248-257. https://doi.org/10.1016/S00344257(02)00041-X.

Nazeer, M., Nichol, J. E., \& Yung, Y. K. (2014). Evaluation of atmospheric correction models and Landsat surface reflectance product in an urban coastal environment. International journal of remote sensing,35(16), 6271-6291. https://doi.org/10.1080/01431161.2014.951742.

Pal, M., \& Mather, P. M. (2005). Support vector machines for classification in remote sensing. International journal of remote sensing, 26(5), 1007-1011. https://doi.org/10.1080/01431160512331314083.

Phinn, S. R., Roelfsema, C. M., \& Mumby, P. J. (2012). Multi-scale, object-based image analysis for mapping geomorphic and ecological zones on coral reefs. International Journal of Remote Sensing, 33(12), 3768-3797. https://doi.org/10.1080/01431161.2011.633122. 
PlanetLab. (2020). Planet Imagery Product Specification.

Purkis, S. J. (2018). Remote Sensing Coral Reefs. United States: Elsevier.

Roelfsema, C. M., Phinn, S. R., \& Joyce, K. E. (2006). Evaluating benthic survey techniques for validating maps of coral reefs derived from remotely sensed images. In Proc 10th Int Coral Reef Symp (Vol. 1, pp. 1771-1780).

Roelfsema, C., Phinn, S., Jupiter, S., Comley, J., \& Albert, S. (2013). Mapping coral reefs at reef to reef-system scales, $10 \mathrm{~s}-1000 \mathrm{~s} \mathrm{~km}^{2}$, using object-based image analysis. International journal of remote sensing,34(18), 6367-6388. https://doi.org/10.1080/01431161.2013.800660.

Suhet S. (2014). Sentinel-2 User Handbook. Europe: ESA European Space Agency.

Voyer, M., Quirk, G., McIlgorm, A., \& Azmi, K. (2018). Shades of blue: what do competing interpretations of the Blue Economy mean for oceans governance?. Journal of Environmental Policy \& Planning, 20(5), 595-616. https://doi.org/10.1080/1523908X.2018.1473153.

Wahidin, N., Siregar, V. P., Nababan, B., Jaya, I., \& Wouthuyzen, S. (2015). Object-based image analysis for coral reef benthic habitat mapping with several classification algorithms. Procedia Environmental Sciences, 24, 222-227. https://doi.org/10.1016/j.proenv.2015.03.029.

Wicaksono, P. (2016). Improving the accuracy of Multispectral-based benthic habitats mapping using image rotations: the application of Principle Component Analysis and Independent Component Analysis. European Journal of Remote Sensing, 49(1), 433 463. https://doi.org/10.5721/EuJRS20164924.

Wicaksono, P., \& Lazuardi, W. (2018). Assessment of PlanetScope images for benthic habitat and seagrass species mapping in a complex optically shallow water environment. International journal of remote sensing,39(17), 5739-5765. https://doi.org/10.1080/01431161.2018.1506951.

Wicaksono, P., Aryaguna, P. A., \& Lazuardi, W. (2019a). Benthic habitat mapping model and cross validation using machine-learning classification algorithms. Remote Sensing, 11(11), 1279. https://doi.org/10.3390/rs11111279.

Wicaksono, P., Fauzan, M. A., Kumara, I. S. W., Yogyantoro, R. N., Lazuardi, W., \& Zhafarina, Z. (2019). Analysis of reflectance spectra of tropical seagrass species and their value for mapping using multispectral satellite images. International Journal of Remote Sensing, 40(23), 8955-8978. https://doi.org/10.1080/01431161.2019.1624866.

Wicaksono, P., Wulandari, S. A., Lazuardi, W., \& Munir, M. (2021). Sentinel-2 images deliver possibilities for accurate and consistent multi-temporal benthic habitat maps in optically shallow water. Remote Sensing Applications: Society and Environment, 23, 100572. https://doi.org/10.1016/j.rsase.2021.100572.

Zambon, M., Lawrence, R., Bunn, A., \& Powell, S. (2006). Effect of alternative splitting rules on image processing using classification tree analysis. Photogrammetric Engineering \& Remote Sensing, 72(1), 25-30. https://doi.org/10.14358/PERS.72.1.25. 
Wahyu Lazuardi \& Pramaditya Wicaksono/ Geosfera Indonesia 6 (3), 2021, 377-397

Zhang, C., Selch, D., Xie, Z., Roberts, C., Cooper, H., \& Chen, G. (2013). Object-based benthic habitat mapping in the Florida Keys from hyperspectral imagery. Estuarine, Coastal and Shelf Science, 134, 88-97. https://doi.org/10.1016/j.ecss.2013.09.018.

Zoffoli, M. L., Frouin, R., \& Kampel, M. (2014). Water column correction for coral reef studies by remote sensing. Sensors, 14(9), 16881-16931. https://doi.org/10.3390/s140916881. 